\title{
TURISMO RURAL E ORDENAMENTO TERRITORIAL: O CASO DE ANALÂNDIA/SP
}

\section{Kleber Andolfato de Oliveira ${ }^{1}$}

RESUMO: Atualmente ocorre um processo chamado por alguns autores como um processo de "revalorização" do rural, esse termo, "revalorização", caracteriza uma nova forma de ver o rural, o mesmo rural que dentro da visão produtivista geralmente é entendido como uma fonte de exploração dos recursos com o objetivo de aumento da produtividade sem muitas vezes considerar o uso adequado dos recursos naturais. As discussões em torno da multifuncionalidade são importantes dentro deste processo de "revalorização" e por isso é satisfatório considerar o turismo rural como uma possibilidade concreta tanto de proteção da natureza, como de fortalecimento cultural das comunidades habitantes no destino do ecoturista ou agroturista. No caso sugerido da cidade de Analândia isso não se apresenta de forma diferente. A cidade de Analândia fica situada dentro da Bacia do rio Corumbataí, e dentro dela se localiza a nascente do mesmo rio que deságua e abastece o Rio Piracicaba, tornando importante o debate sobre as políticas de desenvolvimento do rural na cidade e região.

Palavras-chave: Multifuncionalidade; Turismo rural; Ordenamento territorial

\section{INTRODUÇÃO}

\footnotetext{
${ }^{1}$ Engenheiro Agrônomo. Mestrando no Programa Interunidades em Ecologia Aplicada - ESALQ/CENA. Endereço eletrônico: kadolive@esalq.usp.br e kleberandolfato@yahoo.com.br.
} 
Nos últimos anos as reflexões sobre o conceito de natureza e as formas de atribuir valores á ela tem aumentado. As discussões sobre o uso dos recursos e as formas que os mesmos serão administrados dentro do território é a chave de muitas das falas entre os atores envolvidos dentro do processo, principalmente quando dessas discussões e debates se determinam às ações que irão ser empregadas bem como os resultados econômicos, sociais e ambientais conseqüentes.

Os valores atribuídos à natureza e ao território nem sempre foram os mesmos. Entre os antigos, o pensamento, ou a idéia de natureza e as suas formas de utilização estavam ligados diretamente ao qualitativo, ao valor de uso, entre os gregos, por exemplo, as formas de se relacionar e agir frente a natureza apresenta uma idéia de equilíbrio, o pensamento era contemplativo e por estarem em uma sociedade não mercantilizada não havia a necessidade de se aprimorar as técnicas de trabalho. A produção em si possuía um valor moral, diferente do pensamento moderno que visa a produção. Dentro do pensamento antigo não se derruba cem árvores se é necessário derrubar apenas três. (VERNANT, 1990).

Com o passar do tempo, as formas de produção capitalistas foram modificando o objetivo da criação de valor de uso, como era visto pelos antigos, o quantitativo foi tomando o espaço dos valores qualitativos. Segundo LENOBLE (1990), não existe uma evolução da forma de pensar, mas sim uma ruptura entre o pensamento antigo e o moderno, pois são formas completamente diferentes de ver o mundo (LENOBLE, 1990). Os valores passam a ser, portanto, de acordo com a tecnologia que se é empregada para que se tenha o produto de uso e consumo, a magia da mercadoria ou equivalente de troca como chamado por Marx. (MARX, 1857).

$\mathrm{Na}$ Agricultura um novo processo de mudança de valores esta ocorrendo atualmente. É chamado por alguns autores como um processo de "revalorização" do rural. (SCHENEIDER, 1999). Segundo alguns autores, esse termo, "revalorização", caracteriza uma nova forma de ver o rural, o mesmo rural que dentro da visão produtivista geralmente é entendido como uma fonte de exploração dos recursos com o objetivo de aumento da produtividade sem muitas vezes considerar o uso adequado dos recursos naturais. Esta "revalorização", aponta 
para uma "diversificação das fontes de renda e a combinação de atividades agrícolas e não agrícolas" para elevar o poder aquisitivo das famílias agricultoras e também utilizar de forma sustentável os recursos do território (SCHENEIDER, 1999).

Dentro desta perspectiva, uma das formas que se apresenta como ferramenta de "revalorização" é o turismo rural, ou agroturismo, onde o foco é manter em equilíbrio essa relação de obtenção de renda com o uso sustentável dos recursos naturais, pois assume papel na proteção ambiental, nas trocas culturais e na geração de emprego e renda (Layrargues,2004).

Este trabalho, apresentado ao final da Disciplina de Natureza e Representação no Mundo Ocidental, ministrada pelo Professor Doutor Adalmir Leonidio, pelo Programa de Pósgraduação Interunidades em Ecologia Aplicada, ESALQ/CENA. prentende apresentar uma reflexão sobre o que acontece na cidade de Analândia no Estado de São Paulo, onde o turismo rural tenta emergir como uma forma alternativa de obetenção de renda em uma região tomada pela monocultura de cana de açúcar e eucalipto, que representam hoje o símbolo da idéia produtivista do rural. No entanto, o interesse aqui não é dizer qual o melhor modelo de desenvolvimento para a cidade, mas apenas o analisar como se apresenta esse debate entre os atores envolvidos nesse processo.

\section{ANALÂNDIA E O TURISMO RURAL}

É satisfatório considerar o turismo rural como uma possibilidade concreta tanto de proteção da natureza, como de fortalecimento cultural das comunidades habitantes no destino do ecoturista ou agroturista. Essa perspectiva não só é considerada como um dos princípios básicos norteadores do turismo rural, ao referirem-se ao respeito à conservação ambiental e às comunidades locais, como também foi incorporada no próprio conceito de ecoturismo, que afirma ser esse um: 
"segmento da atividade turística que utiliza, de forma sustentável, o patrimônio natural e cultural, incentiva sua conservação e busca a formação de uma consciência ambientalista através da interpretação do ambiente, promovendo o bem-estar das populações envolvidas." (MMA, 1994) e também dentro do termo de turismo rural "compreendido como sendo toda maneira turística de visitar e conhecer o ambiente rural, enquanto se resgata e valoriza a cultura regional" (EMBRATUR, 1994).

Diante das condições sociais brasileiras, que apresentam um preocupante quadro histórico de concentração de renda, e dado o potencial econômico desse novo mercado, o turismo rural se sobressai com uma importante função social a cumprir: ele pode ser considerado um relevante instrumento de distribuição de renda, mais engajado do que as tímidas menções que se referem à geração de emprego e renda ou melhoria da qualidade de vida das populações envolvidas, como benefícios econômicos indiretos do ecoturismo (Layrargues, 2004).

No Brasil, Mendonça et al (2009) aponta que o turismo rural não está livre de problemas como a falta de planejamento e gestão, baixa capacidade econômica da população, dificuldade de acesso a informações, pouca capacitação profissional e poucas políticas de estímulo à essa prática no território brasileiro. No caso sugerido da cidade de Analândia isso não se apresenta de forma diferente.

Analândia é um dos 15 municípios paulistas considerados estâncias climáticas pelo Estado de São Paulo, por cumprirem determinados pré-requisitos definidos por Lei Estadual. Tal status garante a esses municípios uma verba maior por parte do Estado para a promoção do turismo regional. Possui cerca de 5 mil habitantes mas o fluxo de visitação turistica em épocas como o carnaval e férias escolares chega a 30 mil, população essa que é acolhida nas casas de veraneio ou nas inúmeras pousadas da cidade. A cidade de Analândia fice situada dentro da Bacia do rio Corumbataí, e dentro dela se localiza a nascente do mesmo rio que desagua e abastece o Rio Piracicaba, tornando importante o debate sobre as políticas de desenvolvimento do rural na cidade e região. 

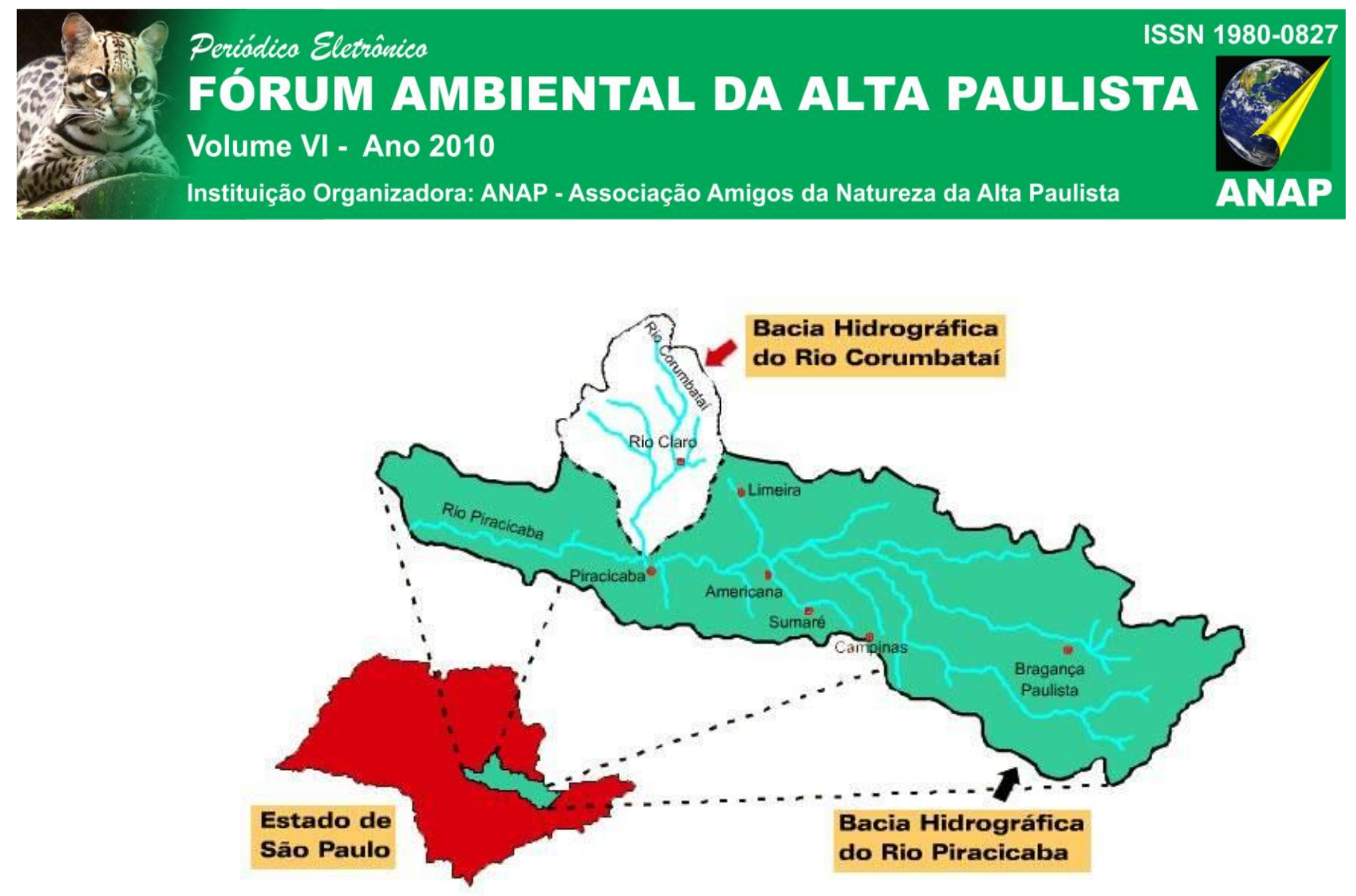

Figura 1 - Localização da Bacia do Rio Corumbataí (CEAPLA, 2010) 


\section{FÓRUM AMBIENTAL DA ALTA PAULISTA}

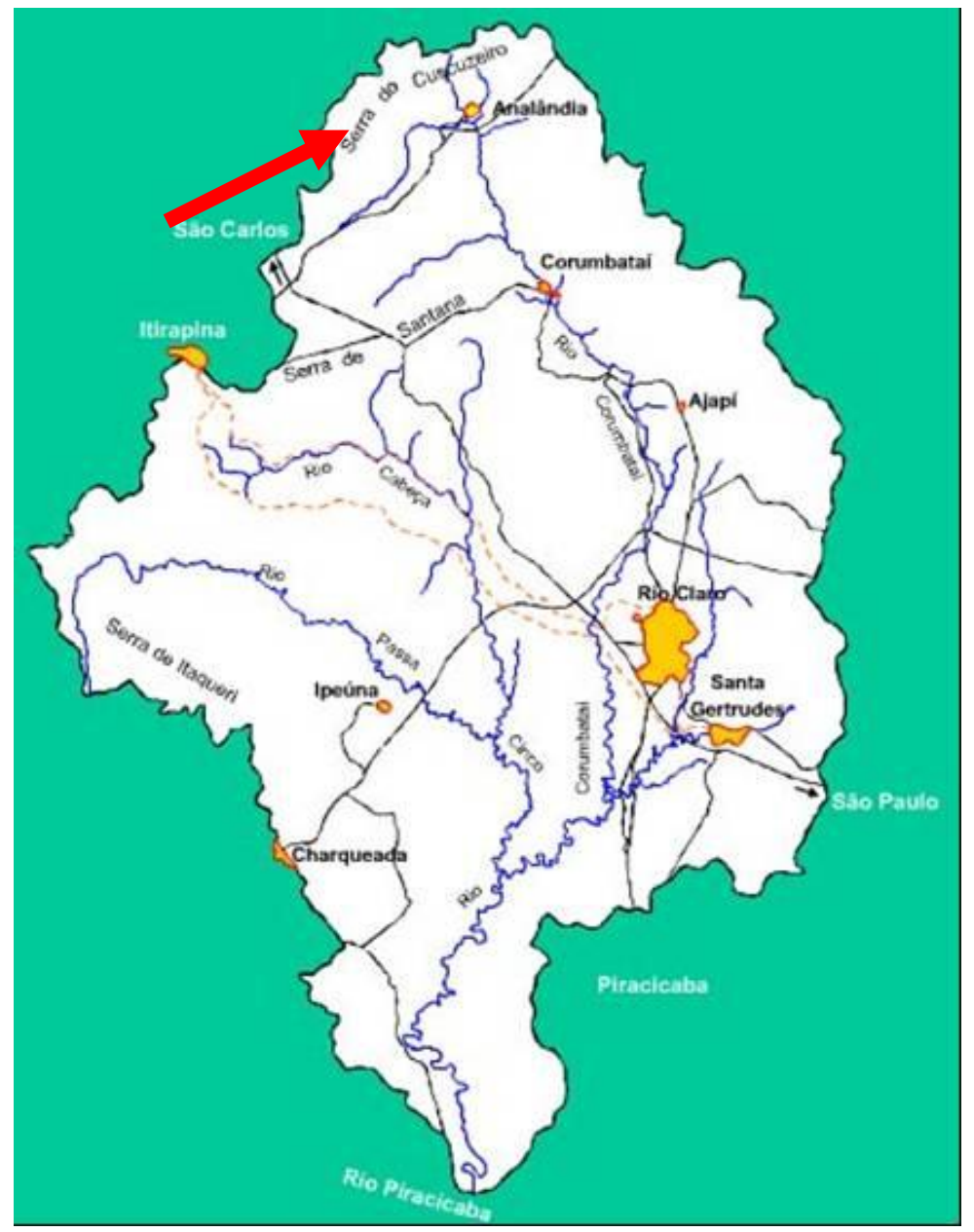

Figura 2. Bacia do Rio Corumbataí (CEAPLA, 2010)

Em entrevista aos atores locais, é possível observar que ainda os maiores impedimentos para que o turismo rural se estabeleça na cidade são as discussões políticas e os interesses econômicos dos proprietários de terras, interesses esses que podem ser modificados, caso, como apontado por alguns através de auxílio e investimento político para a pratica do turismo.

Algumas das poucas tentativas de turismo ainda aparecem de forma lenta. As parcerias com empresas que atuam no setor são estabelecidas entre os donos de propriedades e donos das duas agências da cidade, sem muita influência do poder público, poder público esse que enfrenta de outro lado as discussões daqueles que trabalham com a cana-de- 
açúcar, como por exemplo, a discussão sobre o uso das vias da cidade para a saída dos treminhões em direção as usinas da região, vias essas que passariam pelo centro da cidade onde pontos de potencial turístico como a praça central se encontram.

O principal potencial turístico da cidade é o Morro do Cuscuzeiro (figura 03), que é uma pedra arenítica com cerca de 900 metros de altura onde os praticantes s de montanhismo já possuem mais de 40 vias exploradas, inclusive é um dos pontos utilizados por praticantes de montanhismo que se dirigem até a Cidade de Brotas, que é muito conhecida por oferecer o turismo ecológico de aventura.

O Morro do Cuscuzeiro, esta no centro das discussões como também os demais pontos como O Morro do Camelo e a Pedra do Escorrega. Todos esses pontos são localizados ao redor da cidade e administrados pelos proprietários das terras onde esses pontos se localizam sem uma organização em conjunto dos mesmos. Este potencial turístico da cidade composto por homens e mulheres, de diferentes grupos de idades, são pouco ou praticamente não considerados no planejamento de ações para o desenvolvimento municipal, o que resulta em algumas ocasiões na degradação de ecossistemas, recursos naturais e conseqüentemente do tecido social.

As discussões a cerca do turismo rural na cidade merecem uma atenção maior, é fato que, como apontado pelos atores envolvidos, existe um reflexo da má administração dos recursos naturais na cidade e na região, principalmente nos recursos hídricos que na cidade de Analândia ainda não encontra espaço merecido nas discussões e acertos políticos. 

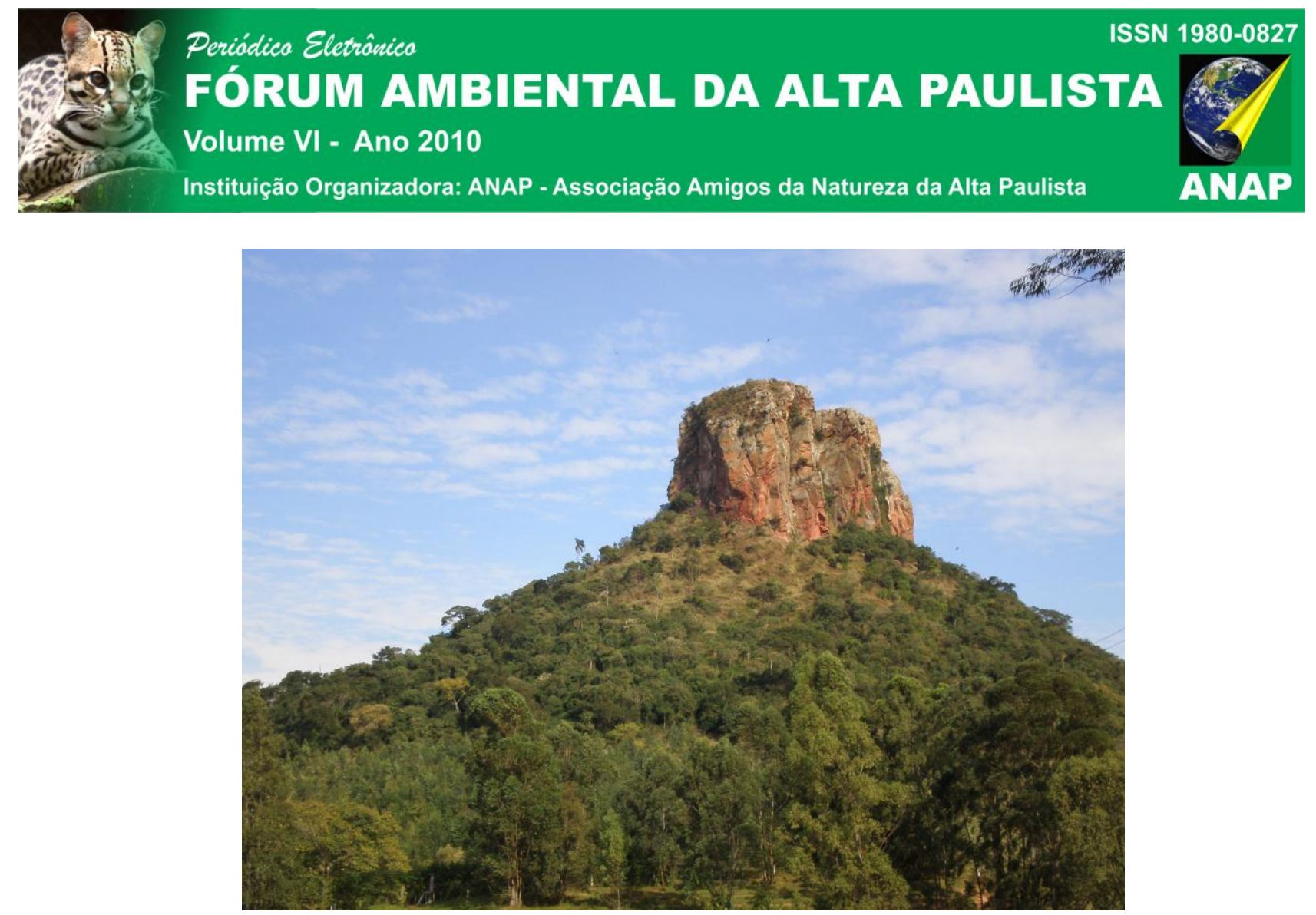

Figura 3 - Morro do Cuscuzeiro em Analândia/SP, vista da propriedade que administra a entrada de visitantes no local.

\section{CONCLUSÃO}

O potencial de turismo rural em Analândia é enorme e promissor. O mercado capitalista produziu valor destruindo a natureza, e seu caráter cíclico agora o faz produzir valor protegendo a natureza. A questão não é saber das verdadeiras intenções do mercado no que diz respeito à proteção do patrimônio natural e cultural, mas como será repartida a riqueza gerada pela exploração econômica da natureza protegida. Do problema que procuramos discutir à idéia que procuramos defender, torna-se explícito o importante papel que as políticas públicas assumem como vetor distributivo para equilibrar as forças do mercado, que por si só, já provaram não serem capazes de repartir a riqueza gerada pela exploração econômica da natureza. Urge que sejam criadas políticas públicas voltadas ao turismo rural e 
que as mesmas de caráter distributivo, onde sejam contempladas não apenas a dimensão ambiental e cultural mas também a socioeconômica da sustentabilidade.

O turismo rural pode ser apenas uma estratégia a mais de conservação da natureza ou um mecanismo de desenvolvimento social que integre a variável ambiental, dependendo do planejamento proposto pelas forças políticas. Em Analândia é necessário maior abertura para esse potencial, é necessário um trabalho de capacitação técnica dos envolvidos e de sensibilização dos gestores para enxergar potencialidades naturais do território pois essas variáveis, constituem, dentre outras questões, os principais motivos que distanciam a população da participação de processos amplos para tomada de decisões em assuntos que afetam a sustentabilidade econômica e ambiental em diversos municípios.

\section{REFERÊNCIAS}

CEAPLA. Atlas Ambiental da Bacia do Rio Corumbataí. Disponível em: < http://ceapla.rc.unesp.br/atlas/>. Acesso em: 15 janeiro de 2010.

EMBRATUR. Diretrizes para uma Política Nacional de Ecoturismo. Brasília, 1994.

LAYRARGUES, Philippe Pomier. A FUNÇÃO SOCIAL DO ECOTURISMO In: Boletim Técnico do Senac. Volume 30, no1. jan./abr. p. 39-45. 2004.

LENOBLE, Robert. História da idéia de natureza. Lisboa: Edições 70, 1990.

MARX , Karl; Elementos fundamentales para la crítica de la economía política. Capitulo: "Formas que preceden a la producción capitalista" .1857.

MENDONÇA, M. C. et al. Turismo no espaço rural: debate e tendência. Disponível em: < http://dae2.ufla.Br/revista2002.htm >. Acesso em: 14 de novembro de 2009.

MMA, Brasil. Diretrizes para a Política Nacional de Ecoturismo. Brasília: 1994.

SCHNEIDER, S. Agricultura familiar e industrialização: pluriatividade e descentralização industrial no Rio Grande do Sul. Porto Alegre: UFRGS, 1999.

VERNANT, Jean-Pierre. Mito e pensamento entre os gregos: estudo de psicologia histórica . Rio de Janeiro, editora Paz e Terra. 2ª edição, 1990. 